ERRATA-CORRIGE

ERMANNO MARCHIONNA

\title{
SULLE VARIETA' INTERSEZIONI COMPLETE
}

\author{
RENDICONTI DEL SEMINARIO MATEMATICO E FISICO DI MILANO \\ Vol. LVIII (1988) pp. 285-307
}

$\begin{array}{cccc}\text { Pag. } & \text { Riga } & \text { Errata } & \text { Corrige } \\ 287 & 2-3 & \begin{array}{c}\text { eventuali sottovarietà } \\ \text { irriducibili di } V_{d} \\ \text { luogo di infiniti }\end{array} & \begin{array}{c}\text { componenti irriducibili } \\ \text { del luogo dei }\end{array} \\ 297 & 2 & \text { costante } p_{0} & \text { costante }\end{array}$

